\title{
Phenolic Composition, Antioxidant and Anticancer Potentials of Extracts from Rosa banksiae Ait. Flowers
}

\author{
Chen Zeng ${ }^{\dagger}$, Siyuan Luo ${ }^{\dagger}$, Shiling Feng, Tao Chen, Lijun Zhou $\odot$, Ming Yuan, Yan Huang, \\ Jinqiu Liao and Chunbang Ding *
}

College of Life Science, Sichuan Agricultural University, Ya'an 625014, China; zc15183819422@126.com (C.Z.); luosiyuan1998@163.com (S.L.); fengshilin@outlook.com (S.F.); chentao293@163.com (T.C.); zhouzhou124@126.com (L.Z.); yuanming@sicau.edu.cn (M.Y.); shirley11hy@163.com (Y.H.); liaojinqiu630@sicau.edu.cn (J.L.)

* Correspondence: dcb@sicau.edu.cn; Tel.: +86-0835-2885560

+ These authors contributed equally to this work.

Academic Editors: Elisa Ovidi and Antonio Tiezzi

Received: 17 June 2020; Accepted: 4 July 2020; Published: 6 July 2020

check for updates

\begin{abstract}
Rosa banksiae Ait. (R. banksiae) is a traditional Chinese folk medicine and an ornamental plant. Most previous studies have focused on cultivation and utilization while there are few research papers on the pharmacological activity of $R$. banksiae. This study aimed to get a better understanding of $R$. banksiae by extracting polyphenols with fractionated extraction technology. The results showed that ethyl acetate phase (EAP) contained the most polyphenols, while water phase (WP) had the least. HPLC analysis indicated that rutin and luteolin-4'-O-glucoside existed in the EAP and butanol phase (BP), but quercetin was only detected in the EAP. Six phenolic compositions were not detected in WB. The antioxidant and anti-tumor abilities of the EAP and BP were excellent. The results revealed that $R$. banksiae possessed a great antioxidant capacity and was rich in polyphenols, thus indicating $R$. banksiae was suitable for being a natural antioxidant and an abundant source of polyphenols.
\end{abstract}

Keywords: Rosa banksiae Ait.; fractionation extraction; polyphenols; HPLC

\section{Introduction}

In the process of human metabolism, a large number of free radicals will be produced. They have strong oxidation, which will cause damage to the function of biofilms and cells in the human body, thereby increasing the risk of cardiovascular disease and cancer, and accelerating the process of human aging [1]. Polyphenols, such as EGCG, quercetin, luteolin and others, were proved to be the principal antioxidants [2-4]. Polyphenols are a kind of secondary metabolites with polyphenol structure which exist widely in plants, and have highly efficient bioactivities. They possess strong antioxidant abilities [5], with obvious effects of anti-mutation [6], anti-cancer [7], and inhibiting hypertensive [8]. Sasaki et al. found that polyphenols were able to protect cells from this kind of mutations, as they can absorb ultraviolet light from sunlight [9]. Polyphenols from betel nut tannins have been used to fight tooth decay, because they bind to the proteins of microbes and viruses, leading to the deactivation of proteins [10]. These bioactivities have something to do with inhibition of microbial metabolic enzymes or complexation of trace metal ions by polyphenols.

Rosa banksiae Ait. (R. banksiae), belonging to Rose family, is a rosaceous perennial evergreen vine, growing to about 20 feet tall, with a long lifespan. R. bankisae is an important, widespread woody plant and a special species in southwest China. As early as 1708, it was recorded in Guang Qunfang $P u$ an ancient book recording flowers written by Wang Hao in Qing dynasty. In traditional Chinese medicine, this plant is effective at relieving pain and stopping bleeding. However, there are few literary reports on pharmacological activity about $R$. banksiae. At present, most of the research on $R$. banksiae are 
focusing on cultivation and utilization, physiology biochemistry and genetic diversity [11,12]. Yu et al. found the chemical compositions of the essential oils from $R$. banksiae flowers were made up with alcohol, terpenoid, ketones and lipid [13]. Some flavonol aglycones were found in the leaves [14]. However, it is worth mentioning that the chemical composition and relative bioactivities of related extracts from this plant have not yet been researched.

In our prophase research, we have found that the flowers from $R$. banksiae are used as a raw material for making pastry, such as moon cakes, and extracts of $R$. banksiae contained a certain level of polyphenols. Surprisingly, related research results have been seldom reported. Thus, the goal of this present study was to identify phenolic compounds of $R$. banksiae and test their antioxidant activity, hoping this research may help us to gain a better understanding of phenolic compounds from $R$. banksiae for industrial applications and pharmacological activities analysis.

\section{Results and Discussion}

\subsection{Polyphenols Content in Different Extraction Phases}

The content of polyphenols from $R$. banksiae in different extraction phases were shown in Table 1. The content in ethyl acetate phase (EAP) was the highest $(759.69 \pm 21.54 \mathrm{mg} / \mathrm{g})$, about 15 times higher than that in water phase (WP) $(48.99 \pm 1.29 \mathrm{mg} / \mathrm{g})$. The content of polyphenols in butanol phase (BP) was $660.75 \pm 22.05 \mathrm{mg} / \mathrm{g}$. The polyphenols contents in EAP and BP were significantly higher than that in WP with $p$ value $<0.001$. In addition, EAP contained more than BP with $p$ value $<0.01$. Methanol and ethanol have often been used as a solvent to extract total polyphenol from plants and the yield was ranging from $2.93 \mathrm{mg} / \mathrm{g}$ to $160.55 \mathrm{mg} / \mathrm{g}$ [4]. In this work, the fractional extraction method could highly enrich the content of polyphenols in butanol and ethyl acetate phase, respectively. The polarity of ethyl acetate phase was larger than the butanol phase. Hence, the result indicated that the polarity of polyphenols in R. banksiae tended to be large and was more similar to the polarity of ethyl acetate.

Table 1. The polyphenols content of three phases.

\begin{tabular}{cc}
\hline Components & Polyphenol Content (mg GAE/g) \\
\hline Water phase & $48.99 \pm 1.29$ \\
Ethyl acetate phase & $759.69 \pm 21.54^{* * * \#}$ \\
Butanol phase & $660.75 \pm 22.05^{* * *}$
\end{tabular}

Note: The polyphenols content was expressed as milligram gallic acid equivalent per gram (mg GAE/g) of dry sample. "**** means the polyphenols contents in ethyl acetate phase and butanol phase were significantly different from that in water phase with $p$ value $<0.001$. "\#\#" means the polyphenols contents in ethyl acetate phase was significantly different from that in butanol phase with $p$ value $<0.01$.

\subsection{Analysis of HPLC}

The HPLC chromatogram of standards was given in Figure 1, and the mixed standards were rutin (1), luteolin-4'-O-glucoside (2), apigenin-7-O-glucoside (3), luteolin (4), quercetin (5), and apigenin (6). Three compositions were identified in three phases by matching their retention times against those of the standards (Figure 1), such as rutin (1), luteolin-4'-O-glucoside (2) and quercetin (5). No composition in the mixed standard was detected in WP (Figure 1).

The phenolic compositions of three phases were shown in Table 2. Rutin only existed in ethyl acetate phase $(10.99 \pm 1.92 \mathrm{mg} / \mathrm{g})$ and butanol phase $(11.06 \pm 2.20 \mathrm{mg} / \mathrm{g})$. The rutin content in ethyl acetate and butanol phases was not significantly different according to student's T test $(p>0.05)$. The luteolin-4'-O-glucoside in ethyl acetate phase was significantly higher than butanol phase with $p$ value $<0.001$. However, the quercetin was only detected in ethyl acetate phase $(5.73 \pm 0.24 \mathrm{mg} / \mathrm{g})$.

Polyphenols wildly exist in rosaceous plants. JE Lee et al. found 12 identified polyphenols compositions in chokeberry, such as quercetin 3-O-rutinoside, apigenin 7, 4'-di-O-rhamnoside and quercetin rhamnosylhexoside [15]. In this study, luteolin-4'-O-glucoside was found in $R$. banksiae with a high content. Therefore, $R$. banksiae could be a potential source for luteolin- $4^{\prime}-O$-glucoside. 

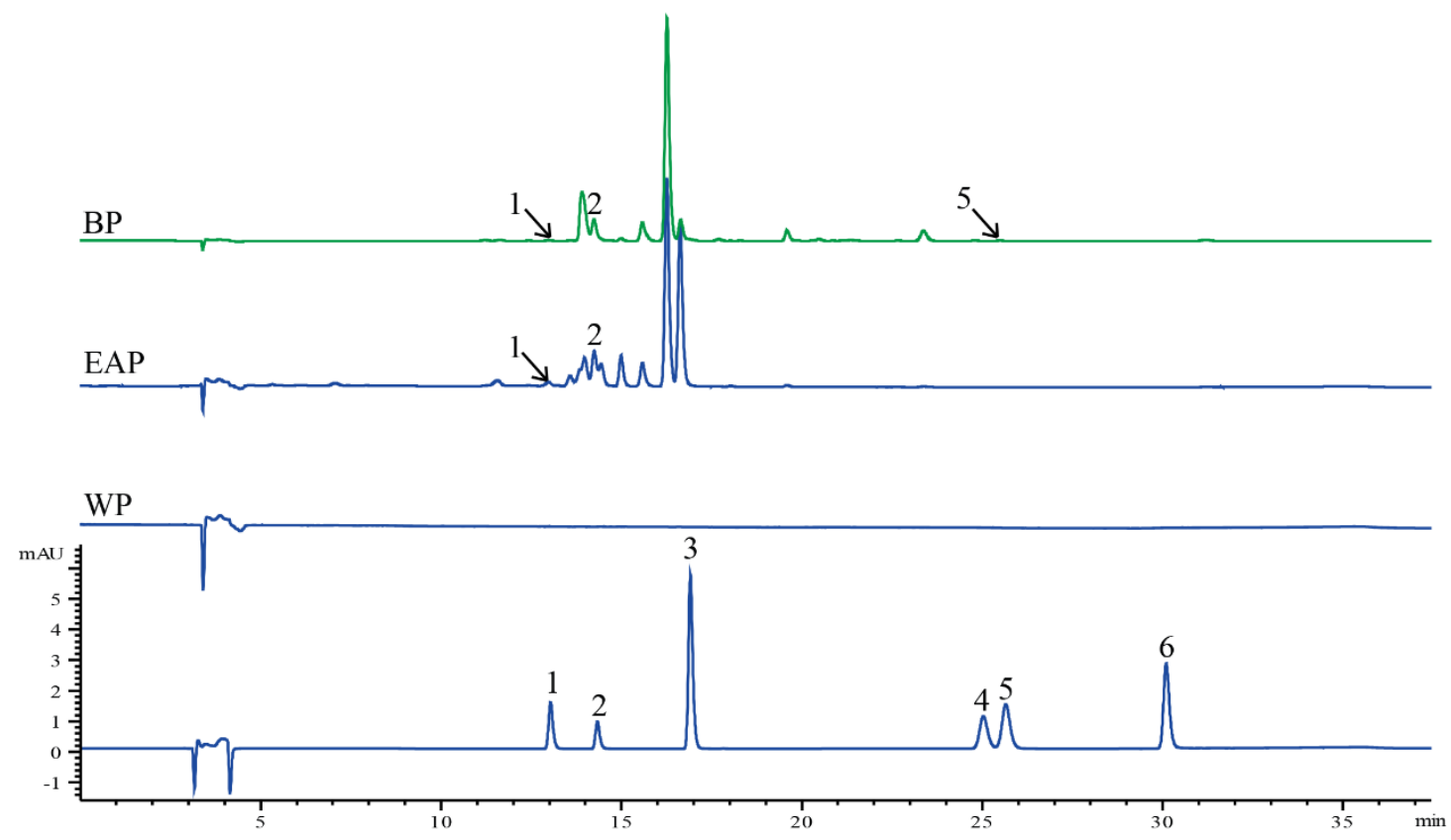

Figure 1. The high performance liquid chromatography (HPLC) of mixed standard. Rutin (1), luteolin-4'-O-glucoside (2), apigenin-7-O-glucoside (3), luteolin (4), quercetin (5), and apigenin (6).

Table 2. The phenolic compositions of three phases.

\begin{tabular}{|c|c|c|c|c|c|}
\hline Phenolic Compositions & Regression Curve & Correlation Coefficient & Water Phase & Ethyl Acetate Phase & Butanol Phase \\
\hline rutin & $y=2533.5 x+2.4153$ & 0.999 & nd & $10.99 \pm 1.92$ & $11.06 \pm 2.20^{\mathrm{ns}}$ \\
\hline luteolin-4'-O-glucoside & $y=2240.2 x+0.8639$ & 0.999 & nd & $368.83 \pm 40.43$ & $102.60 \pm 4.04^{* * *}$ \\
\hline apigenin-7-O-glucoside & $y=5886.8 x+3.0264$ & 0.998 & nd & nd & nd \\
\hline luteolin & $y=1978.4 x+1.8608$ & 0.998 & nd & nd & nd \\
\hline quercetin & $y=4691.3 x-3.6269$ & 0.999 & nd & $5.73 \pm 0.24$ & nd \\
\hline apigenin & $y=9596.4 x+1.5547$ & 0.999 & nd & nd & nd \\
\hline
\end{tabular}

Note: All results were expressed as milligram per gram $(\mathrm{mg} / \mathrm{g})$ of dry sample. "nd" means not detected. "ns" means the content of rutin in ethyl acetate and butanol phases is not significantly different by student' $\mathrm{T}$ test. "****" means the luteolin-4'-O-glucoside in butanol phase is significantly different from that in ethyl acetate phase with $p$ value $<0.001$.

\subsection{Analysis of Antioxidant Activity in Different Extraction Phases}

DPPH free radical scavenging capacity was widely applied to assess the bioactivity of natural substances [16]. As shown in Figure 2a, the DPPH radical scavenging ability rates of three phases promoted with the increasing concentration and tended to be flatten at a high concentration. The clearance rate of water phase was lower than $30 \%$, showing a weak antioxidant ability. The clearance rates of ethyl acetate phase and butanol phase were almost the same and close to Vc. The maximum clearance rates of three phases at $1.0 \mathrm{mg} / \mathrm{mL}$ were $27.85 \%$ (WP), $93.45 \%$ (EAP) and $93.46 \%(\mathrm{BP})$, respectively. $\mathrm{IC}_{50}$ was $1.43 \mathrm{mg} / \mathrm{mL}(\mathrm{WP}), 0.31 \mathrm{mg} / \mathrm{mL}$ (EAP) and $0.34 \mathrm{mg} / \mathrm{mL}(\mathrm{BP})$, respectively.

An ascending absorbance meant a promoting total reducing power. Different extraction phases had certain total reduction capacity, showing a good dose-effect relationship with the increasing of sample concentration. As shown in Figure 2b, the absorbance of EAP and BP was higher than WP but lower than Vc. Three phases all had certain total antioxidant capacity, but much lower than positive control Vc (Figure 2c). When the concentration reached $1.0 \mathrm{mg} / \mathrm{mL}$, the total antioxidant capacity of three phases were $5.905 \mathrm{U} / \mathrm{mg}(\mathrm{WP}), 31.62 \mathrm{U} / \mathrm{mg}$ (EAP) and $31.42 \mathrm{U} / \mathrm{mg}(\mathrm{BP})$, respectively. Ferric ion reducing antioxidant power (FRAP) was widely used to screen high-antioxidant ability substances. The FRAP of EAP was not significantly different from BP, but both of them were significantly higher than WP $(p<0.0001)$. When the concentration reached $1.0 \mathrm{mg} / \mathrm{g}$, the FRAP of three phases was $0.7114 \mathrm{mmol} \mathrm{FE} / \mathrm{mg}$ (WP), $3.195 \mathrm{mmol} \mathrm{FE} / \mathrm{mg}$ (EAP) and $2.862 \mathrm{mmol} \mathrm{FE} / \mathrm{mg}(\mathrm{BP})$, respectively. 

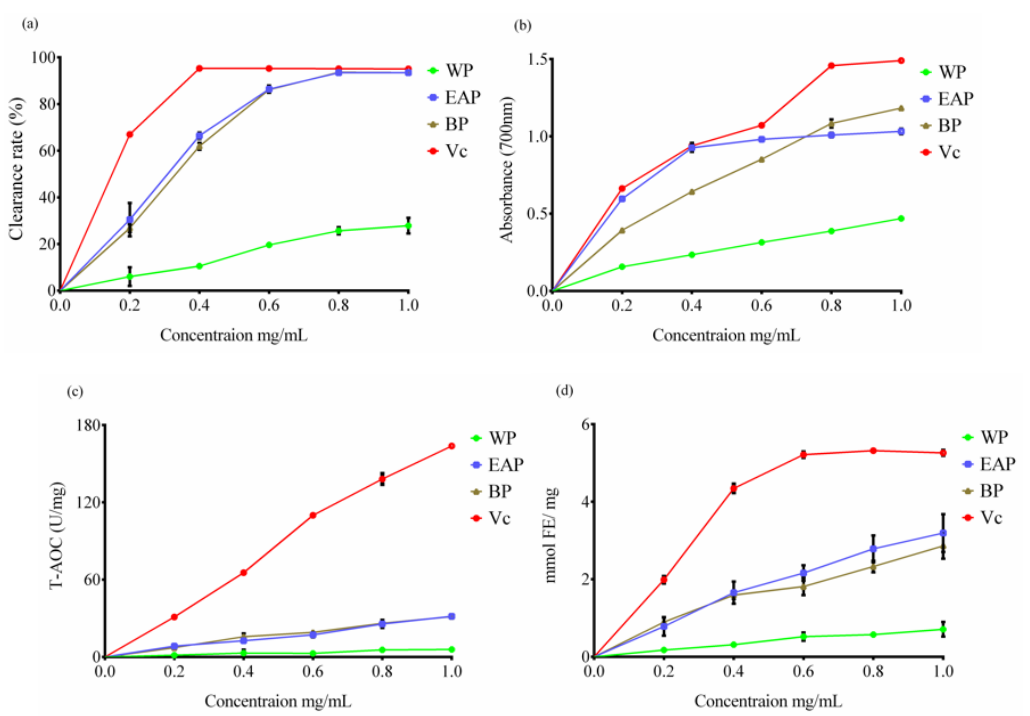

Figure 2. The antioxidant ability of three phases (a) 2,2-Diphenyl-1-picryl-hydrazyl (DPPH) free radical scavenging capacity, (b) total reduction capacity, (c) total antioxidant capacity (T-AOC) and (d) ferric ion reducing antioxidant power (FRAP).

Polyphenols from natural plants have been proved to possess an effective antioxidant ability [16]. As shown in Tables 1 and 2, EAP and BP contained a high content of polyphenols while WB had the lowest content. The antioxidant ability results showed the EAP and BP were higher than WP. Therefore, the antioxidant ability of $R$. banksiae may connect with polyphenols content. Lu et al. and Higdon et al. obtained similar results that indicate that polyphenols possess effective antioxidant ability [5,17]. Süzgeç-Selçuk et al. proved that the luteolin- $4^{\prime}$-O-glucoside possessed an excellent antioxidant ability [18]. EAP and BP were rich in luteolin-4'-O-glucoside; hence, the great antioxidant activity of EAP and BP may relate to their high content of luteolin-4'-O-glucoside.

\subsection{Analysis of Anti-Tumor Activity in Different Extraction Phases}

As shown in Figure 3, the growth of Hela cells treated with EAP and BP was obviously inhibited as the increasing sample concentrations. Nevertheless, WP exhibited a weak suppression ability on the proliferation of Hela cells. Particularly, EAP possessed a strong restrain effect compared with the other two phases. Polyphenols were proved to be the principal drugs against cancer [19]. As shown in Table 1, three phases contained different content of polyphenols. The content in WP was the lowest; therefore, WP could not restrain Hela cells. Luteolin- $4^{\prime}$-O-glucoside was also reported to possess a strong inhibitory efficacy on Hela cells [20]. Moreover, EAP contained more luteolin-4'-O-glucoside than BP (Table 1); hence, the restrain effect of EAP was the strongest.

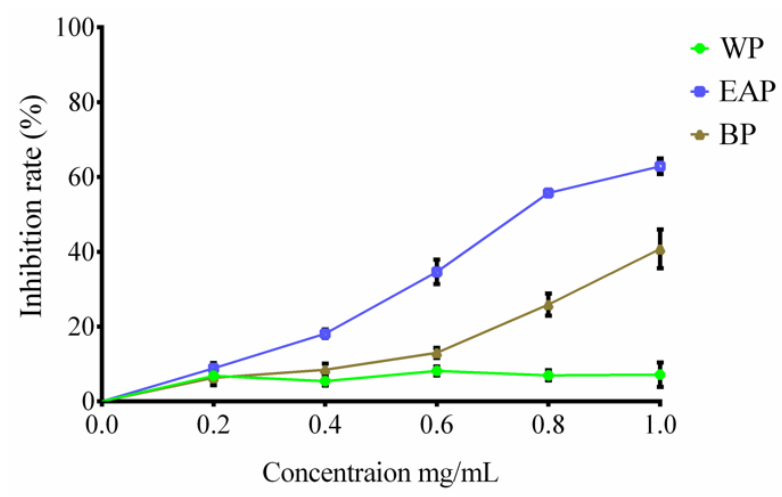

Figure 3. The inhibition effect of three phases on Hela cells treated for $48 \mathrm{~h}$. 


\section{Materials and Methods}

\subsection{Materials and Reagents}

Flowers from Rosa banksiae Ait. were picked up at the campus of Sichuan Agricultural University, Sichuan, Ya'an, China, at $29^{\circ} 58^{\prime} 49^{\prime \prime} \mathrm{N}, 120^{\circ} 59^{\prime} 19^{\prime \prime}$ E.

2,2-Diphenyl-1-picryl-hydrazyl (DPPH) was purchased from Sigma Chemical Co. (St. Louis, MO, USA). Butanol, ethyl acetate and gallic acid were purchased from the Chengdu Kelong Chemical Factory (Chengdu, China). FRAP assay kit was purchased from Beyotime Biotechnology (Shanghai, China). Total antioxidant capacity assay kit was purchased from Nanjing Jiancheng Bioengineering Institute (Nanjing, China). All chemicals were analytical grade.

\subsection{Fractionation Extraction of R. Banksiae Flowers}

A quantity of $80 \mathrm{~g} R$. banksiae flowers were mixed with $1 \mathrm{~L}$ water and extracted at $99{ }^{\circ} \mathrm{C}$ for $4 \mathrm{~h}$. The water extract was filtered through a decompress filter, decanted in the separation funnel. Equal volume ethyl acetate was added for the first-time extraction for $2 \mathrm{~h}$. After separating the liquid, the ethyl acetate phase of $R$. banksiae was obtained. Then, equal volume butanol was added to the water phase for the second-time extraction for $2 \mathrm{~h}$. Then the separating liquid butanol phase was complete. Water phase (WP), ethyl acetate phase (EAP), and butanol phase (BP) were concentrated by a freeze drier. The concentrations were set at $-20^{\circ} \mathrm{C}$ for following experiments.

\subsection{Determination of Polyphenols Content}

The polyphenols content was measured by Folin-phenol reagent method. Briefly, $0.2 \mathrm{~mL}$ sample solution was mixed with $0.2 \mathrm{~mL} 25 \%$ folin-phenol reagent placed at dark for $5 \mathrm{~min}$, then $0.2 \mathrm{~mL} 7.5 \%$ sodium carbonate $(w / v)$ was added into the solution placed at dark for $5 \mathrm{~min}$. Finally, the solution was diluted with up-water to $2 \mathrm{~mL}$. After standing for $20 \mathrm{~min}$, the absorbance of reaction solution was read at $700 \mathrm{~nm}$. The polyphenols content was calculated according to the standard curve made with gallic acid as reference. The polyphenols content was expressed as milligram gallic acid equivalent per gram (mg GAE/g) of dry sample.

\subsection{HPLC Analysis}

Phenolic compositions in three phases were analyzed by high performance liquid chromatography (HPLC) with C18 column and HPLC system. The chromatographic analysis was performed using an Agilent 1260 HPLC (Agilent Technologies, Santa Clara, CA, USA) coupled with a UV-Vis DAD detector at $350 \mathrm{~nm}$ and a C18 reversed-phase column $(5.0 \mu \mathrm{m}, 150 \mathrm{~mm} \times 4.6 \mathrm{~mm})$. The phenolic compositions were analyzed by a gradient elution program using (A) Aqueous phosphoric acid $(0.15 \%$, emphv/v) and (B) acetonitrile (containing $0.1 \%$ acetic acid $v / v)$ were used as the mobile phase and the gradient program was set as follows: 10-16\% B (0-3 min), 16-30\% B (3-20 min), $30-40 \%$ B (20-25 min), 40-16\% B (25-30 min), and 16-10\% B (30-40 min). The flow rate was $0.5 \mathrm{~mL} / \mathrm{min}$, and the temperature of the column was kept at $30^{\circ} \mathrm{C}$. The phenolic concentrations of rutin, luteolin-4'-O-glucoside, apigenin-7-O-glucoside, luteolin, quercetin, and apigenin were determined using a standard curve, and all results were presented as milligrams per gram $(\mathrm{mg} / \mathrm{g})$ of dry matter.

\subsection{Determination of Antioxidant Activities}

\subsubsection{Determination of DPPH Free Radical Scavenging Capacity}

The three phase extracts of $R$. banksiae were resolved in water, ethyl acetate and butanol to different concentrations, respectively. The determination of DPPH radical scavenging ability of three extracts was based on the method described by Villano with slight modifications [14]. Briefly, $40 \mu \mathrm{L}$ ascorbic acid $\left(\mathrm{Vc}_{\mathrm{c}}\right)(0.2-1.0 \mathrm{mg} / \mathrm{mL})$, which served as positive control, and $R$. banksiae samples $(0.2-1.0 \mathrm{mg} / \mathrm{mL})$ were respectively added into $140 \mu \mathrm{L}$ DPPH ethanol solution $(0.4 \mathrm{mM})$. The mixtures were incubated 
at room temperature in the dark for $10 \mathrm{~min}$, then absorbance of mixture was measured at $517 \mathrm{~nm}$ by microplate reader (Spectramax M2, San Francisco, USA). The following formula was used to calculate the DPPH radical scavenging ability:

$$
\text { DPPH radical scavenging activity }(\%)=(1-\mathrm{A} 1 / \mathrm{A} 0) \times 100 \%
$$

where A1 is the absorbance of the reaction solution with the sample and A0 is the control group replaced with distilled water.

\subsubsection{Determination of Total Reduction Capacity}

The total reduction capacity of $R$. banksiae was determined by the potassium ferricyanide reduction method. $0.2 \mathrm{~mL}$ of $R$. banksiae samples $(0.2-1.0 \mathrm{mg} / \mathrm{mL})$ were mixed with $0.5 \mathrm{~mL}$ PBS $(0.2 \mathrm{M})$ and $0.5 \mathrm{~mL}$ $\mathrm{K}_{3}\left[\mathrm{Fe}(\mathrm{CN})_{6}\right](1 \%, w / v)$. The mixtures were placed at $50{ }^{\circ} \mathrm{C}$ for $20 \mathrm{~min}$, after that, $0.5 \mathrm{~mL} \mathrm{TCA}(10 \%, w / v)$ was instantly added into and solutions were cooled at $0{ }^{\circ} \mathrm{C}$ for $5 \mathrm{~min}$. A volume of $0.5 \mathrm{~mL}$ supernatant was mixed with $0.1 \mathrm{~mL} \mathrm{FeCl}_{3}(0.1 \%, w / v)$ and $0.5 \mathrm{~mL}$ distilled water. After $10 \mathrm{~min}$ of standing at room temperature, the absorbance of reaction solution was read at $700 \mathrm{~nm}$. The increasing of absorbance was meaning a promoting reducing power.

3.5.3. Determination of Ferric Ion Reducing Antioxidant Power (FRAP) and Total Antioxidant Capacity (T-AOC)

The FRAP and T-AOC were tested by the FRAP and T-AOC assay kits, and the process was operated according to the kit instructions. Vc was used as the positive control. The results of FRAP were expressed as millimoles of ferrous sulfate equivalent per $\mathrm{mg}$ (mM FE/mg) of dry sample. The T-AOC results were expressed as unit per milligram $(\mathrm{U} / \mathrm{mg})$ of dry sample.

\subsection{Anti-Cancer Assay}

\subsubsection{Cell Culture}

Hela cells were kindly provided by Stem Cell Bank, Chinese Academy of Sciences, Shanghai, China. Hela cells were cultured in dulbecco's modified eagle medium (DMEM) containing 10\% FBS (purchased from Gibco, Carlsbad, CA, USA) at $37^{\circ} \mathrm{C}$ in a humidified atmosphere of $95 \%$ air and $5 \%$ $\mathrm{CO}_{2}$.

\subsubsection{Inhibition Effect on Hela Cells}

The inhibition effect of three phases on the proliferation of Hela cells was determined by CCK-8 assay (purchased from Boster Biological Technology Co. Ltd., Wuhan, China). Briefly, three phases were resolved in DMSO, and filtered by $0.22 \mu \mathrm{m}$ filter membrane. The cells were planted in 96-well microplate at the density of $10^{5}$ per milliliter and maintained at $37^{\circ} \mathrm{C}$ for $6 \mathrm{~h}$ before added with sample solutions (the concentration of DMSO was less than 1\%). After $48 \mathrm{~h}$ treatment, the solutions were completely replaced with new fresh medium. $10 \mu \mathrm{L} \mathrm{CCK}-8$ was added into the wells and the plate was placed at $37^{\circ} \mathrm{C}$ for $30 \mathrm{~min}$ before reading the absorbance at $450 \mathrm{~nm}$. The inhibition rate was calculated according to the following formula:

$$
\text { Inhibition rate }(\%)=(1-\mathrm{A} 1 / \mathrm{A} 2) \times 100 \%
$$

where the A1 was the absorbance of treated group; A2 was the absorbance of control group.

\subsection{Statistical Analysis}

The data were analyzed by one-way analysis of variance (ANOVA) and Student's test with GraphPad Prism 6 (GraphPad Software, Inc., La Jolla, CA, USA). All values were expressed as 
mean \pm SD. All experiments were carried out in triplicate. $p$ value less than 0.05 was considered as statistically significant.

\section{Conclusions}

Previous studies ignored the chemical compositions and pharmacological capacity of Rosa banksiae. However, the polyphenols content from $R$. banksiae flowers was firstly determined and shown to exist at a high value in EAP, followed by BP and WP. HPLC was successfully applied to identified phenolic components such as rutin, luteolin-4'-O-glucoside and quercetin in three phases. Furthermore, the antioxidant activities of EAP as well as BP were higher than WP and close to Vc. Moreover, EAP and BP showed a strong inhibitory efficacy on Hela cells compared with the effect of WP. This may be caused by the different polyphenols content in three phases. Above all, Rosa banksiae contained a high level of polyphenols and possessed a strong antioxidant ability, thus providing a theoretical basis for potentially economical utilization of $R$. banksiae in the field of food and health products.

Author Contributions: All authors contributed to the study conception and design. Resources: Y.H. and J.L.; Methodology: L.Z. and T.C.; Formal analysis and investigation: C.Z. and S.L.; Writing-review: S.F. and M.Y.; Supervision: C.D. The first draft of the manuscript was written by C.Z. and S.L. and all authors commented on previous versions of the manuscript. All authors have read and agreed to the published version of the manuscript.

Funding: This research received no external funding.

Conflicts of Interest: The authors declare that they have no conflict of interest.

\section{References}

1. Cadenas, E.; Davies, K.J.A. Mitochondrial free radical generation, oxidative stress, and aging. Free Radic. Biol. Med. 2000, 29, 222-230. [CrossRef]

2. Hirano, R.; Sasamoto, W.; Matsumoto, A.; Itakura, H.; Igarashi, O.; Kondo, K. Antioxidant Ability of Various Flavonoids against DPPH Radicals and LDL Oxidation. J. Nutr. Sci. Vitaminol. 2001, 47, 357-362. [CrossRef] [PubMed]

3. Seelinger, G.; Merfort, I.; Schempp, C.M. Anti-Oxidant, Anti-Inflammatory and Anti-Allergic Activities of Luteolin. Planta Med. 2008, 74, 1667-1677. [CrossRef] [PubMed]

4. Assefa, A.D.; Keum, Y.S.; Saini, R.K. A comprehensive study of polyphenols contents and antioxidant potential of 39 widely used spices and food condiments. J. Food Meas. Charact. 2018, 12, 1548-1555. [CrossRef]

5. Lu, Y.; Yeap, L.F. Antioxidant and radical scavenging activities of polyphenols from apple pomace. Food Chem. 2000, 68, 81-85. [CrossRef]

6. Katiyar, S.K.; Agarwal, R.; Mukhtar, H. Protection against malignant conversion of chemically induced benign skin papillomas to squamous cell carcinomas in SENCAR mice by a polyphenolic fraction isolated from green tea. Cancer Res. 1993, 53, 5409-5412. [CrossRef] [PubMed]

7. Takuo, O.; Kazuko, M.; Hikoya, H. Inhibitory effect of tannins on direct-acting mutagens. Chem. Pharm. Bull. 1984, 32, 3755-3758. [CrossRef]

8. Lin, T.C.; Hsu, F.L.; Cheng, J.T. Antihypertensive Activity of Corilagin and Chebulinic Acid, Tannins from Lumnitzera, racemose. J. Nat. Prod. 1993, 56, 629-632. [CrossRef]

9. Sasaki, Y.F.; Imanishi, H.; Ohta, T.; Watanabe, M.; Matsumoto, K.; Shirasu, Y. Suppressing effect of tannic acid on UV and chemically induced chromosome aberrations in cultured mammalian cells. Agric. Biol. Chem. 1988, 52, 2423-2428. [CrossRef]

10. Iwawoto, M.; Uchino, K.; Toukairin, T.; Kawaguchi, K.; Tatebayashi, T.; Ogawara, H.; Tonosaki, Y. The Growth Inhibition of Streptococcus mutans by 5'-Nucleotidase Inhibitors from Areca catechu L. Chem. Pharm. Bull. 1991, 39, 1323-1324. [CrossRef]

11. Han, W. Cuttage Technology Research of Rosa Hybrida and Rosa Banksiae. Anhui Agric. Sci. Bull. 2007, 13, 76-77, 139. [CrossRef]

12. Wang, M.; Zhang, C.; Li, M.; Gao, X. The complete chloroplast genome sequence of Rosa banksiae var. normalis (Rosaceae). Mitochondr. DNA Part B 2019, 4, 969-970. [CrossRef]

13. Yu, A.; Wang, X.; Yang, X. Chemical composition of the essential oils of flowers of Rosa banksiae from China. Chem. Nat. Compd. 2007, 43, 728-729. [CrossRef] 
14. Nowak, R.; Tuzimski, T. A solid-phase extraction-thin-layer chromatographic-fiber optical scanning densitometric method for determination of flavonol aglycones in extracts of rose leaves. J. Planar Chromatogr. 2005, 18, 437-442. [CrossRef]

15. Lee, J.E.; Kim, G.S.; Park, S.; Kim, Y.H.; Kim, M.B.; Lee, W.S.; Jeong, S.W.; Lee, S.J.; Jin, J.S.; Shin, S.C. Determination of chokeberry (Aronia melanocarpa) polyphenol components using liquid chromatography-tandem mass spectrometry: Overall contribution to antioxidant activity. Food Chem. 2014, 146, 1-5. [CrossRef] [PubMed]

16. Konwarh, R.; Pramanik, S.; Kalita, D.; Mahanta, C.L.; Karak, N. Ultrasonication-A complementary 'green chemistry' tool to biocatalysis: A laboratory-scale study of lycopene extraction. Ultrason. Sonochem. 2012, 19, 292-299. [CrossRef] [PubMed]

17. Higdon, J.V.; Frei, B. Tea Catechins and Polyphenols: Health Effects, Metabolism, and Antioxidant Functions. Crit. Rev. Food Technol. 2003, 43, 89-143. [CrossRef] [PubMed]

18. Süzgeç-Selçuk, S.; Birteksöz, A.S. Flavonoids of Helichrysum chasmolycicum and its antioxidant and antimicrobial activities. S. Afr. J. Bot. 2011, 77, 170-174. [CrossRef]

19. Rothwell, J.A.; Knaze, V.; Zamora-Ros, R. Polyphenols: Dietary assessment and role in the prevention of cancers. Curr. Opin. Clin. Nutr. 2017, 20, 512. [CrossRef] [PubMed]

20. Goodarzi, S.; Tabatabaei, M.J.; Jafari, R.M.; Shemirani, F.; Tofighi, Z. Cuminum cyminum fruits as source of luteolin-7- O -glucoside, potent cytotoxic flavonoid against breast cancer cell lines. Nat. Prod. Res. 2020, 11, 1602-1606. [CrossRef] [PubMed]

Sample Availability: Samples of the compounds are not available from the authors.

(C) 2020 by the authors. Licensee MDPI, Basel, Switzerland. This article is an open access article distributed under the terms and conditions of the Creative Commons Attribution (CC BY) license (http://creativecommons.org/licenses/by/4.0/). 